\title{
Clinical outcome of empiric antimicrobial therapy of bacteremia due to extended-spectrum beta-lactamase producing Escherichia coli and Klebsiella pneumoniae
}

\author{
Vikas P Chaubey', Johann DD Pitout 2,4,5, Bruce Dalton 1,7, Terry Ross², Deirdre L Church', Daniel B Gregson 1,2,5 and \\ Kevin B Laupland*1,2,3,6
}

\begin{abstract}
Background: Prompt administration of adequate empiric antimicrobial therapy is a major determinant influencing the outcome of serious infections. The objective of this study was to describe empiric antimicrobial therapy employed and assess its effect on the outcome of patients bacteremic with extended-spectrum beta-lactamase (ESBL) producing Escherichia coli and Klebsiella pneumoniae.

Findings: A retrospective surveillance study of all patients with bacteremias caused by ESBL-producing $E$. coli and $K$. pneumoniae (EK-ESBL) from 2000-2007 in the Calgary Health Region was conducted. Data were available for 79 episodes of bacteremia among 76 patients. Forty-four (56\%) were male, the median age was 70.0 yrs [interquartile range (IQR) 60.6-70.1 yrs], and 72 (91\%) episodes were E. coli. Seventy-four episodes (94\%) were treated with empiric therapy within the first 48 hours. A non-statistically significant increased mortality occurred in those treated empirically with a beta-lactam/beta-lactamase inhibitor combination (6/16;38\% vs. 10/53; $18 \% ; p=0.063)$ while empiric carbapenem therapy was associated with lower mortality (0/10 died vs. 16/53 (30\%), $p=0.089)$. Only $42(53 \%)$ episodes received adequate therapy within the first 48 hours. The median time to first adequate antibiotic therapy was 41.0 hours [IQR 5.8-59.5] ( $n=75)$. The case-fatality rate was not different among those that received adequate compared to inadequate therapy by 48 hours as compared to inadequate empiric therapy $(9 / 42 ; 21 \%$ vs. $7 / 37 ; 19 \% ; p=1.0)$.

Conclusion: Inadequate empiric therapy is common among patients with EK-ESBL bacteremia in our region but was not associated with adverse mortality outcome.
\end{abstract}

\section{Introduction}

Organisms elaborating extended-spectrum beta-lactamases (ESBL) are now found worldwide [1]. Bloodstream infections caused by these microbes are increasing in the community [2,3] and in hospitals [4-6]. These organisms are typically multi-drug resistant [7] and the risk of inadequate empiric therapy [8-11] while awaiting susceptibility results is high. ESBL-bacteremias are also a risk factor for adverse outcome $[10,11]$. Previous studies have typically been conducted in highly selected populations including specific age ranges, location of acquisition (i.e. commu- nity or hospital). Furthermore, these infections have typically been assessed in tertiary care referral centres. These results may not reflect practices in populations at large and generalization elsewhere may be limited.

Few studies have included a broad range of ages, location of acquisition, and multiple centres, and none have been from Canada. It was therefore of interest to describe the empiric therapy of bacteremias caused by Escherichia coli and Klebsiella pneumonia elaborating ESBL enzymes (EK-ESBL) in a non-selected population of patients in a large Canadian health region.

\footnotetext{
* Correspondence: kevin.laupland@albertahealthservices.ca

1 Department of Medicine, University of Calgary, Calgary, Canada

Full list of author information is available at the end of the article
} 


\section{Methods}

\section{Study population}

Prior to a recent restructuring as Alberta Health Services, The Calgary Health Region (CHR) administered virtually all medical and surgical care to the residents of the cities of Calgary and Airdrie and a large surrounding area (population 1.2 million) in the Province of Alberta, Canada. All patients with bacteremias caused by EK-ESBL organisms from January 1, 2000 to December 31, 2007 in the CHR were included.

\section{Study protocol}

An active, surveillance cohort design was utilized. As previously described, surveillance for EK-ESBL bacteremias was conducted by Calgary Laboratory Services [12]. International Statistical Classification of Disease and Health Related Problems (ICD) codes were translated into Charlson Comorbidity Scores using standardized algorithms [13-15] and an online macro [16]. All antimicrobial therapies prescribed were determined using the regional pharmacy database [17]. EK-ESBL infections were defined by the isolation of these organisms from one or more sets of aseptically obtained blood culture bottles. The presence or absence of ESBL-producing E. coli or $K$. pneumoniae cultures obtained from non-blood sites within \pm 48 hours of the index incident blood culture draw was also assessed. Repeated isolation from blood within 365 days was considered to be the same incident infection and thereafter as new episodes.

Empiric therapy was defined as that therapy initiated prior to the availability of blood culture results and sensitivities. Time to first therapy was defined as the time from blood culture draw to receipt of the first dose of antibiotics. Adequate therapy was defined by the receipt of a standard parenteral dose of an antimicrobial to which the organism was fully susceptible in vitro based on Clinical and Laboratory Standards Institute (CLSI) breakpoints or a standard oral dose of an antimicrobial with high bioavailability by this route, to which the organism was also fully susceptible. ESBL-producing organisms were assumed to be resistant to cefazolin, ceftriaxone, ceftazidime, aztreonam, and cefipime. If the patient was given adequate antibiotics before or at the time of the blood culture draw then the time to first adequate therapy was recorded as zero hours. Definitions of nosocomial, healthcare associated and community-acquired infections have been previously described [12].

\section{Laboratory Methods}

Clinical isolates were cultured, speciated, and tested for antimicrobial susceptibility by standard techniques [18]. At Calgary Laboratory Services, all Enterobacteriaceae isolates are routinely screened for ESBL production. Minimum inhibitory concentrations (MICs) were determined by Vitek $2^{\text {ma }}$ (Vitek AMS; bioMérieux Vitek Systems Inc., Hazelwood, MO). The quality control strains used for this part of the study were E. coli ATCC 25922, E. coli ATCC 35218 and Pseudomonas aeruginosa ATCC 27853. The presence of ESBLs was detected in clinical isolates of E. coli by using the CLSI criteria for ESBL screening and disk confirmation tests [18]. Disks for ESBL confirmation tests were obtained from Oxoid Inc. (Nepean, Ontario, Canada). K. pneumoniae ATCC 700603 and E. coli ATCC 25922 were used as positive and negative controls, respectively. Isoelectric focusing (IEF) which included cefotaxime hydrolysis and inhibitor profiles in polyacrylamide gels was performed on freeze-thaw extracts as previously described [19]. Polymerase chain reaction (PCR) amplification for $b l a_{C T X-M s}, b l a_{O X A s}, b l a_{T E M s}, b l a_{S H V}$, was carried out on the isolates with a GeneAmp 9700 ThermoCycler instrument (Applied Biosystems, Norwalk, Con) using PCR conditions and primers as previously described $[19,20]$. Automated sequencing was performed on the PCR products with the ABI Prism 3100 Genetic analyzer (Applied Bio-systems, Norwalk, Con) as previously described $[21,22]$.

\section{Statistical analysis}

Analysis was performed using Stata version 10.0 (Stata Corp, College Station, TX). Non-normally distributed data were described using medians with interquartile ranges (IQR) and compared using the Mann-Whitney test. Categorical data were compared using the Fisher's Exact or chi ${ }^{2}$ tests. P-values less than 0.05 were considered significant and those between 0.05 and 0.1 were considered to represent a trend.

\section{Results \\ Population Characteristics}

During the study period, 90 episodes of EK-ESBL bacteremias were identified. Detailed treatment and outcome data were available for analysis in $79(88 \%)$ episodes occurring among 76 patients. Forty-four (56\%) episodes occurred in males and the median age was 70 (IQR 60.670.1) years. The median crude Charlson Comorbidity Score was 2 (IQR 0-3) and the median age-adjusted score was 4 (IQR 2-6). Twenty-four (30\%) of the bacteremias were nosocomial; $33(42 \%)$ were healthcare associated and $22(28 \%)$ were community acquired. The most common comorbid conditions were renal disease, $\mathrm{n}=19$ (24\%); malignancy, $\mathrm{n}=16(20 \%)$; diabetes without complications, $\mathrm{n}=9(11 \%)$, and diabetes with complications, $\mathrm{n}=10(13 \%)$ as shown in Table 1 .

\section{Microbiological Characteristics}

Of the 79 bacteremic episodes 72 (91\%) were E. coli and 7 (9\%) were K. pneumoniae. One Klebsiella pneumoniae bacteremia was polymicrobial with Pseudomonas aerugi- 
Table 1: Characteristics of the population.

\begin{tabular}{|c|c|c|c|c|}
\hline FACTOR & $\begin{array}{l}\text { CASE FATALITY WITH } \\
\text { FACTOR }\end{array}$ & $\begin{array}{l}\text { CASE FATALITY } \\
\text { WITHOUT } \\
\text { FACTOR }\end{array}$ & $\begin{array}{l}\text { RELATIVE RISK } \\
(95 \% \mathrm{Cl})\end{array}$ & P-VALUE \\
\hline Male & $6 / 44(14 \%)$ & $10 / 35(29 \%)$ & $0.48(0.19-1.19)$ & 0.09 \\
\hline $\begin{array}{l}\text { Charlson } \geq \text { median(4) } \\
\text { (Age Adjusted) }\end{array}$ & $12 / 45(27 \%)$ & $4 / 34(12 \%)$ & $2.27(0.80-6.41)$ & 0.09 \\
\hline $\begin{array}{l}\text { Cerebrovascular } \\
\text { Disease }\end{array}$ & $1 / 3(33 \%)$ & $15 / 76(20 \%)$ & $1.69(0.32-8.91)$ & NS \\
\hline $\begin{array}{l}\text { Congestive Heart } \\
\text { Failure }\end{array}$ & $1 / 7(14 \%)$ & $15 / 72(21 \%)$ & $0.69(0.11-4.45)$ & NS \\
\hline $\begin{array}{l}\text { Chronic Pulmonary } \\
\text { Disease }\end{array}$ & $0 / 1(0 \%)$ & $16 / 78(21 \%)$ & 0.00() & NS \\
\hline Dementia & $1 / 4(25 \%)$ & $15 / 75(20 \%)$ & $1.25(0.22-7.24)$ & NS \\
\hline $\begin{array}{l}\text { Diabetes without } \\
\text { complications }\end{array}$ & $0 / 9(0 \%)$ & $16 / 70(23 \%)$ & 0.00() & NS \\
\hline $\begin{array}{l}\text { Diabetes with } \\
\text { complications }\end{array}$ & $1 / 10(10 \%)$ & $15 / 69(22 \%)$ & $0.46(0.07-3.11)$ & NS \\
\hline Paraplegia & $0 / 1(0 \%)$ & $16 / 78(21 \%)$ & 0.00() & NS \\
\hline Mild Liver Disease & $3 / 4(75 \%)$ & $13 / 75(17 \%)$ & $4.32(2.04-9.17)$ & 0.03 \\
\hline Severe Liver Disease & $2 / 4(50 \%)$ & $14 / 75(19 \%)$ & $2.68(0.90-7.95)$ & NS \\
\hline Malignancy & $5 / 21(24 \%)$ & $11 / 58(19 \%)$ & $1.25(0.49-3.19)$ & NS \\
\hline Metastatic & $0 / 1(0 \%)$ & $16 / 78(21 \%)$ & 0.00() & NS \\
\hline Myocardial Infarction & $1 / 3(33 \%)$ & $15 / 76(20 \%)$ & $1.69(0.32-8.91)$ & NS \\
\hline $\begin{array}{l}\text { Peripheral Vascular } \\
\text { Disease }\end{array}$ & $0 / 1(0 \%)$ & $16 / 78(21 \%)$ & 0.00() & NS \\
\hline Peptic Ulcer Disease & $0 / 2(0 \%)$ & $16 / 77(21 \%)$ & 0.00() & NS \\
\hline Rheumatologic & $2 / 4(50 \%)$ & $14 / 75(19 \%)$ & $2.68(0.90-7.95)$ & NS \\
\hline Renal & $5 / 19(26 \%)$ & $11 / 60(18 \%)$ & $1.43(0.57-3.61)$ & NS \\
\hline Dialysis & $2 / 5(40 \%)$ & $14 / 74(19 \%)$ & $2.11(0.65-6.83)$ & NS \\
\hline
\end{tabular}


nosa. One Escherichia coli bacteremia was polymicrobial with a viridans group streptococcus. Neither of these second organisms affected adequacy of antimicrobial therapy as they were sensitive to all major classes of antibiotics. Thirty-nine bacteremias (49\%) were primary; 38 (48\%) were from a urinary source; 2 (3\%) resulted from pneumonias and $1(1 \%)$ patient had a biliary source. One patient had two sources documented (one urinary and the other biliary). Although typing was not performed for $K$. pneumoniae isolates, E. coli ESBL's were typed as 1 CTX-M-2, 1 CTX-M-3, 27 CTX-M-14, 35 CTX-M-15, 5 SHV-2, 1 TEM-52 and 1 was unknown.

\section{Description of therapy}

The median time to initial empiric therapy was 4.9 (IQR 0 -13.9) hours and the median time to first adequate antibiotic therapy was 41 (IQR 5.8-59.5) hours. Seventy-four $(94 \%)$ of episodes had received empiric antibiotic therapy by 48 hours, but only $42(53 \%)$ were prescribed an adequate antibiotic regimen by this time point. Specific details of empiric therapy and initial antibiotics chosen are described in Table 2 and the adequacy of therapy and first adequate antibiotics utilized are shown in Table 3.

\section{Outcomes}

Overall 63 cases (80\%) survived to discharge. The casefatality rate associated with an episode of $E$. coli bacteremia was $22 \%(16 / 72)$ whereas this was $0 \%(0 / 7)$ for $K$. pneumoniae. Those who received adequate therapy by 8 hours $(6 / 22 ; 27 \%$ vs. $6 / 53 ; 11 \% ; \mathrm{p}=0.088)$ and 24 hours (7/28; $25 \%$ vs. $5 / 42 ; 12 \% ; \mathrm{p}=0.096)$ trended towards a higher likelihood of death. However, there was no significant difference in mortality when comparing those patients who were adequately treated to those inadequately treated by 48 hours $(9 / 42 ; 21 \%$ vs. $7 / 37 ; 19 \% ; \mathrm{p}=$ 1.0). Statistical trends toward a worse clinical outcome was associated with the following factors: age-adjusted Charlson score greater than the median $(12 / 45 ; 27 \%$ vs. $4 /$ $34 ; 12 \%$ mortality; $\mathrm{p}=0.087)$, female gender $(10 / 35 ; 28.5 \%$ vs. $6 / 38 ; 13.6 \%$ mortality; $\mathrm{p}=0.087)$; and having been

Table 2: Description of empiric therapy *.

\begin{tabular}{|c|c|c|c|c|}
\hline FACTOR & $\begin{array}{l}\text { CASE FATALITY WITH } \\
\text { FACTOR }\end{array}$ & $\begin{array}{l}\text { CASE FATALITY } \\
\text { WITHOUT FACTOR }\end{array}$ & RELATIVE RISK (95\% CI) & P-VALUE \\
\hline Empiric by $\mathrm{t}=0$ & $7 / 29(24 \%)$ & $9 / 50(18 \%)$ & $1.34(0.56-3.22)$ & NS \\
\hline Empiric by $\mathrm{t}=8$ hours & $12 / 48(25 \%)$ & $4 / 31(13 \%)$ & $1.94(0.69-5.47)$ & NS \\
\hline Empiric by $t=24$ hours & $14 / 68(21 \%)$ & $2 / 11(18 \%)$ & $1.13(0.30-4.32)$ & NS \\
\hline Empiric by $t=48$ hours & $15 / 74(20 \%)$ & $1 / 5(20 \%)$ & $1.01(0.17-6.20)$ & NS \\
\hline Empiric at $\mathrm{t}>48$ hours & $0 / 3(0 \%)$ & $16 / 76(21 \%)$ & 0.00 & NS \\
\hline Never received empiric therapy. & $0 / 1(0 \%)$ & $16 / 78(21 \%)$ & $\ldots$ & $\ldots$ \\
\hline \multicolumn{5}{|l|}{ Empiric Treatment Class } \\
\hline Carbapenem & $0 / 10(0 \%)$ & $16 / 69(24 \%)$ & 0.00() & 0.09 \\
\hline Aminoglycoside & $1 / 7(14 \%)$ & $15 / 72(21 \%)$ & $0.67(0.10-4.41)$ & NS \\
\hline Fluoroquinolone & $3 / 13(23 \%)$ & $13 / 66(20 \%)$ & $1.17(0.39-3.54)$ & NS \\
\hline $\begin{array}{l}\text { Beta-lactam/Beta-lactamase } \\
\text { inhibitor combination }\end{array}$ & $6 / 16(38 \%)$ & $10 / 63(16 \%)$ & $2.36(1.01-5.53)$ & 0.06 \\
\hline Cephalosporin & $5 / 30(17 \%)$ & $11 / 49(22 \%)$ & $0.74(0.29-1.93)$ & NS \\
\hline Beta-lactam & $0 / 5(0 \%)$ & $16 / 74(22 \%)$ & 0.00() & NS \\
\hline
\end{tabular}

\footnotetext{
* Empiric therapy was defined as that therapy initiated prior to the availability of blood culture results and sensitivities.
} 
Table 3: Description of adequacy of therapy **.

\begin{tabular}{|c|c|c|c|c|}
\hline FACTOR & $\begin{array}{l}\text { CASE FATALITY WITH } \\
\text { FACTOR }\end{array}$ & $\begin{array}{l}\text { CASE FATALITY } \\
\text { WITHOUT FACTOR }\end{array}$ & RELATIVE RISK (95\% CI) & P-VALUE \\
\hline Adequate by $\mathrm{t}=0$ & $1 / 11(9 \%)$ & $15 / 68(22 \%)$ & $0.41(0.06-2.81)$ & NS \\
\hline Adequate by $t=8$ hours & $6 / 22(27 \%)$ & $10 / 57(18 \%)$ & $1.55(0.64-3.76)$ & 0.09 \\
\hline Adequate by $t=24$ hours & $7 / 28(25 \%)$ & $9 / 51(18 \%)$ & $1.42(0.59-3.39)$ & 0.10 \\
\hline Adequate by $\mathrm{t}=48$ hours & $9 / 42(21 \%)$ & $7 / 37(18 \%)$ & $1.13(0.47-2.74)$ & NS \\
\hline Adequate at $t>48$ hours & $3 / 33(9 \%)$ & $13 / 46(28 \%)$ & $0.32(0.10-1.04)$ & NS \\
\hline Never received adequate therapy & $4 / 4(100 \%)$ & $12 / 75(16 \%)$ & $6.25(3.72-10.5)$ & 0.01 \\
\hline \multicolumn{5}{|l|}{ First Adequate Antibiotic Choice } \\
\hline $\begin{array}{l}\text { Beta-lactam/Beta-lactamase } \\
\text { inhibitor combination }\end{array}$ & $6 / 28(21 \%)$ & $10 / 51(20 \%)$ & $1.09(0.44-2.69)$ & NS \\
\hline Carbapenem & $4 / 30(13 \%)$ & $12 / 49(24 \%)$ & $0.54(0.19-1.53)$ & NS \\
\hline Fluoroquinolone & $1 / 4(25 \%)$ & $15 / 75(20 \%)$ & $1.25(0.22-7.24)$ & NS \\
\hline Aminoglycoside & $1 / 10(10 \%)$ & $15 / 69(22 \%)$ & $0.46(0.07-3.11)$ & NS \\
\hline Sulfa & $1 / 3(33 \%)$ & $15 / 76(20 \%)$ & $1.69(0.32-8.91)$ & NS \\
\hline
\end{tabular}

** Adequate therapy was defined by the receipt of a standard parenteral dose of an antimicrobial to which the organism was fully susceptible in vitro based on Clinical and Laboratory Standards Institute (CLSI) breakpoints or a standard oral dose of an antimicrobial with high bioavailability by this route, to which the organism was also fully susceptible.

treated empirically with a beta-lactam/beta-lactamase inhibitor combination $(6 / 16 ; 38 \%$ vs. $10 / 53 ; 18 \%$ mortality; $\mathrm{p}=0.063)$. There was no association between ESBL type and mortality. Of 10 patients empirically treated with a carbapenem none died vs. 16/53 (30\%) patients having died who were not empirically treated with a carbapenem $(p=0.089)$. Of note empiric cephalosporin therapy was not associated with a worse outcome $(5 / 30$; $16 \%$ vs. $11 / 49 ; 22 \%, p=0.375)$. The case-fatality rate was highest for patients with nosocomial infections (38\%; 9/ $24)$, followed by those with healthcare associated infections $(15 \% ; 5 / 33)$ and community-acquired infections (9\%; $2 / 22$ patients); $\mathrm{p}=0.046$.

\section{Discussion}

This study describes the contemporary treatment of ESBL-producing E. coli and K. pneumoniae in a large Canadian health region. Although we found high rates of inadequacy of therapy, we did not observe an increased risk for death associated with inadequate therapy.
It should be noted that our data was also analyzed using only patients with $E$. coli bacteremia as $K$. pneumoniae represented such a small proportion of the overall cohort (data not shown). The major conclusions were unchanged. The small number of $K$. pneumoniae isolates included prohibits generalization to bacteremias caused by this organism.

It is a curious finding that when comparing those who received adequate therapy by 8 and 24 hours to those that were inadequately treated that there was a trend in favour of inappropriate therapy. It is widely accepted that early appropriate antibiotic therapy should be protective $[23,24]$. We speculate that this observation may be explained by sicker patients (who are at higher risk for death) may be more likely to get broader and more prompt empiric antimicrobial as a result of their clinical condition. However, it is a limitation of our study that we did not collect data to measure severity of illness to confirm this suspicion. The possibility also exists that this was a spurious finding, as the difference was no longer 
observed by 48 hours of observation. It must be recognised that our study involved a relatively small cohort of patients and was underpowered to detect a clinically significant difference in outcome.

In our study the most common type of ESBL enzyme is the CTX-M type, specifically in our region CTX-M-14 and CTX-M-15. CTX-M type enzymes in general and CTX-M-15 in particular have been shown in previous literature [1] to be the most widely disseminated ESBL enzymes. Our study reaffirms these finding. More studies are needed to determine why these ESBL types are more prevalent than others.

Piperacillin/tazobactam is the most commonly used broad-spectrum antibiotic in our region (data not shown). Our study suggests a poorer prognosis experienced by patients treated with this agent and this has been previously been demonstrated by others $[25,26]$. It is notable that 5 of 6 patients treated with piperacillin/ tazobactam who died were sensitive by CLSI $(<=16 \mathrm{mg} /$ $\mathrm{L})$ and EUCAST $(<=8 \mathrm{mg} / \mathrm{L})$ breakpoints. These data suggest that piperacillin/tazobactam should not be used for serious infections due to EK-ESBL even in the setting of in vitro susceptibility. Most authors agree that carbapenems are the drugs of choice [26-29] for serious infections caused by organisms that elaborate ESBLs. Our observation that all 10 patients who received empiric carbapenem therapy survived, while not proving, supports this principle. Overall EK-ESBL bacteremias are relatively uncommon. The challenge to researchers and clinicians is to select patients appropriately for early broad-spectrum therapy in an attempt to improve outcome while minimizing over treatment and the associated risks of antimicrobial resistance.

\section{Competing interests}

The authors declare that they have no competing interests.

\section{Authors' contributions}

VC performed the primary data analysis and manuscript draft. JDDP performed the molecular typing of ESBL enzymes. BD and TR contributed to data collection and database management.

DLC and DBG contributed to study design and data collection. KL contributed to study conception and design, data collection, analysis, and manuscript drafting. All authors critically reviewed and approved the manuscript.

\section{Acknowledgements}

This study was funded by an unrestricted research grant from Merck-Frosst Canada Inc. The authors had full autonomy in the design, conduct, reporting, and decision to publish.

\section{Author Details}

'Department of Medicine, University of Calgary, Calgary, Canada, ${ }^{2}$ Department of Pathology and Laboratory Medicine, University of Calgary, Calgary, Canada, ${ }^{3}$ Department of Critical Care Medicine, University of Calgary, Calgary, Canada, ${ }^{4}$ Department of Microbiology and Infectious Diseases, University of Calgary, Calgary, Canada, ${ }^{5}$ Calgary Laboratory Services, Alberta Health Services, Calgary, Canada, ${ }^{6}$ Centre for Anti-microbial Resistance, Alberta Health Services, Calgary, Canada and 'Department of Pharmacy Services, Alberta Health Services, Calgary, Canada
Received: 25 September 2009 Accepted: 27 April 2010

Published: 27 April 2010

\section{References}

1. Pitout JD, Laupland KB: Extended-spectrum beta-lactamase-producing Enterobacteriaceae: an emerging public-health concern. Lancet Infect Dis 2008, 8:159-166.

2. Apisarnthanarak A, Kiratisin P, Mundy LM: Predictors of mortality from community-onset bloodstream infections due to extended-spectrum beta-lactamase-producing Escherichia coli and Klebsiella pneumoniae. Infect Control Hosp Epidemiol 2008, 29:671-674.

3. Kang $\mathrm{Cl}$, Cheong $\mathrm{HS}$, Chung DR, Peck KR, Song JH, Oh MD, et al.: Clinical features and outcome of community-onset bloodstream infections caused by extended-spectrum beta-lactamase-producing Escherichia coli. Eur J Clin Microbiol Infect Dis 2008, 27:85-88.

4. Coque TM, Baquero F, Canton R: Increasing prevalence of ESBLproducing Enterobacteriaceae in Europe. Euro Surveill 2008, 13:

5. Jones RN, Jenkins SG, Hoban DJ, Pfaller MA, Ramphal R: In vitro efficacy of six cephalosporins tested against Enterobacteriaceae isolated at 38 North American medical centres participating in the SENTRY Antimicrobial Surveillance Program, 1997-1998. Int J Antimicrob Agents 2000, 15:111-118

6. Winokur PL, Canton R, Casellas JM, Legakis N: Variations in the prevalence of strains expressing an extended-spectrum betalactamase phenotype and characterization of isolates from Europe, the Americas, and the Western Pacific region. Clin Infect Dis 2001, 32(Suppl 2):S94-103.

7. Schwaber MJ, Navon-Venezia S, Schwartz D, Carmeli Y: High levels of antimicrobial coresistance among extended-spectrum-betalactamase-producing Enterobacteriaceae. Antimicrob Agents Chemother 2005, 49:2137-2139.

8. Kim BN, Woo JH, Kim MN, Ryu J, Kim YS: Clinical implications of extended-spectrum beta-lactamase-producing Klebsiella pneumoniae bacteraemia. J Hosp Infect 2002, 52:99-106.

9. Lautenbach E, Patel JB, Bilker WB, Edelstein PH, Fishman NO: Extendedspectrum beta-lactamase-producing Escherichia coli and Klebsiella pneumoniae: risk factors for infection and impact of resistance on outcomes. Clin Infect Dis 2001, 32:1162-1171.

10. Schwaber MJ, Navon-Venezia S, Kaye KS, Ben-Ami R, Schwartz D, Carmeli $Y$ : Clinical and economic impact of bacteremia with extendedspectrum-beta-lactamase-producing Enterobacteriaceae. Antimicrob Agents Chemother 2006, 50:1257-1262.

11. Schwaber MJ, Carmeli Y: Mortality and delay in effective therapy associated with extended-spectrum beta-lactamase production in Enterobacteriaceae bacteraemia: a systematic review and metaanalysis. J Antimicrob Chemother 2007, 60:913-920

12. Laupland KB, Gregson DB, Church DL, Ross T, Pitout JD: Incidence, risk factors and outcomes of Escherichia coli bloodstream infections in a large Canadian region. Clin Microbiol Infect 2008, 14:1041-1047.

13. Quan H, Sundararajan V, Halfon P, Fong A, Burnand B, Luthi JC, et al.: Coding algorithms for defining comorbidities in ICD-9-CM and ICD-10 administrative data. Med Care 2005, 43:1130-1139.

14. Quan H, Li B, Saunders LD, Parsons GA, Nilsson Cl, Alibhai A, et al. Assessing validity of ICD-9-CM and ICD-10 administrative data in recording clinical conditions in a unique dually coded database. Health Serv Res 2008, 43:1424-1441.

15. Sundararajan V, Henderson T, Perry C, Muggivan A, Quan H, Ghali WA: New ICD-10 version of the Charlson comorbidity index predicted inhospital mortality. J Clin Epidemiol 2004, 57:1288-1294.

16. Hall WH, Ramachandran R, Narayan S, Jani AB, Vijayakumar S: An electronic application for rapidly calculating Charlson comorbidity score. BMC Cancer 2004, 4:94

17. Parkins MD, Sabuda DM, Elsayed S, Laupland KB: Adequacy of empirical antifungal therapy and effect on outcome among patients with invasive Candida species infections. J Antimicrob Chemother 2007, 60:613-618.

18. Clinical and Laboratory Standards Institute: Performance Standards for Antimicrobial Susceptibility Testing. In 18th informational supplement M100-S18. 2009 Wayne, CLSI; 2008.

19. Pitout JD, Church DL, Gregson DB, Chow BL, McCracken M, Mulvey MR, et al: Molecular epidemiology of CTX-M-producing Escherichia coli in the 
Calgary Health Region: emergence of CTX-M-15-producing isolates. Antimicrob Agents Chemother 2007, 51:1281-1286.

20. Pitout JD, Hamilton N, Church DL, Nordmann P, Poirel L: Development and clinical validation of a molecular diagnostic assay to detect CTXM-type beta-lactamases in Enterobacteriaceae. Clin Microbiol Infect 2007, 13:291-297.

21. Pitout JD, Gregson DB, Campbell L, Laupland KB: Molecular characteristics of extended-spectrum-beta-lactamase-producing Escherichia coli isolates causing bacteremia in the Calgary Health Region from 2000 to 2007: emergence of clone ST131 as a cause of community-acquired infections. Antimicrob Agents Chemother 2009, 53:2846-2851.

22. Pitout JD, Hanson ND, Church DL, Laupland KB: Population-based laboratory surveillance for Escherichia coli-producing extendedspectrum beta-lactamases: importance of community isolates with blaCTX-M genes. Clin Infect Dis 2004, 38:1736-1741.

23. Kumar A, Roberts D, Wood KE, Light B, Parrillo JE, Sharma S, et al:: Duration of hypotension before initiation of effective antimicrobial therapy is the critical determinant of survival in human septic shock. Crit Care Med 2006, 34:1589-1596.

24. Harbarth S, Garbino J, Pugin J, Romand JA, Lew D, Pittet D: Inappropriate initial antimicrobial therapy and its effect on survival in a clinical trial of immunomodulating therapy for severe sepsis. Am J Med 2003, 115:529-535.

25. Burgess DS, Hall RG, Lewis JS, Jorgensen JH, Patterson JE: Clinical and microbiologic analysis of a hospital's extended-spectrum betalactamase-producing isolates over a 2-year period. Pharmacotherapy 2003, 23:1232-1237.

26. Paterson DL, Ko WC, von GA, Mohapatra S, Casellas JM, Goossens H, et al. Antibiotic therapy for Klebsiella pneumoniae bacteremia: implications of production of extended-spectrum beta-lactamases. Clin Infect Dis 2004, 39:31-37.

27. Lautenbach E, Strom BL, Bilker WB, Patel JB, Edelstein PH, Fishman NO: Epidemiological investigation of fluoroquinolone resistance in infections due to extended-spectrum beta-lactamase-producing Escherichia coli and Klebsiella pneumoniae. Clin Infect Dis 2001, 33:1288-1294

28. Lautenbach E, Metlay JP, Bilker WB, Edelstein PH, Fishman NO: Association between fluoroquinolone resistance and mortality in Escherichia coli and Klebsiella pneumoniae infections: the role of inadequate empirical antimicrobial therapy. Clin Infect Dis 2005, 41:923-929.

29. Endimiani A, Luzzaro F, Perilli M, Lombardi G, Coli A, Tamborini A, et al:: Bacteremia due to Klebsiella pneumoniae isolates producing the TEM52 extended-spectrum beta-lactamase: treatment outcome of patients receiving imipenem or ciprofloxacin. Clin Infect Dis 2004, 38:243-251.

doi: 10.1186/1756-0500-3-116

Cite this article as: Chaubey et al., Clinical outcome of empiric antimicrobial therapy of bacteremia due to extended-spectrum beta-lactamase producing Escherichia coli and Klebsiella pneumoniae BMC Research Notes 2010, 3:116

\section{Submit your next manuscript to BioMed Central} and take full advantage of:

- Convenient online submission

- Thorough peer review

- No space constraints or color figure charges

- Immediate publication on acceptance

- Inclusion in PubMed, CAS, Scopus and Google Scholar

- Research which is freely available for redistribution

Submit your manuscript at www.biomedcentral.com/submit
C Biomed Central 